\title{
Association between dioxin concentrations in breast milk and food group intake in Vietnam
}

\author{
Kae Saito · Dang Duc Nhu • Hiroyuki Suzuki - Teruhiko Kido · Rie Naganuma • \\ Chiaki Sakakibara $\cdot$ Kenji Tawara $\cdot$ Muneko Nishijo $\cdot$ Hideaki Nakagawa \\ Kaoru Kusama $\cdot$ Phung Tri Dung $\cdot$ Le Hong Thom $\cdot$ Nguyen Ngoc Hung
}

Received: 20 March 2009/Accepted: 3 August 2009/Published online: 15 September 2009

(C) The Japanese Society for Hygiene 2009

\begin{abstract}
Objectives To clarify the association between dioxin concentrations in breast milk and food group intake in herbicide-sprayed and nonsprayed areas in Vietnam.

Methods This survey was conducted in August 2007 in sprayed and nonsprayed areas, respectively. The interviews were performed using a questionnaire to obtain information on personal characteristics and usual dietary intake. Eighty mothers of sprayed area and 42 mothers of nonsprayed area participated in the study. Breast milk was analyzed for concentration of polychlorinated dibenzo- $p$-dioxins (PCDDs) and polychlorinated dibenzofurans (PCDFs).

Results Multiple regression analysis showed that location (sprayed or nonsprayed area) has the highest association with the toxic equivalents (TEQ)-PCDDs, TEQ-PCDFs,
\end{abstract}

K. Saito $(\bowtie) \cdot$ D. D. Nhu $\cdot$ H. Suzuki

Graduate School of Medical Science, Kanazawa University,

5-11-80 Kodatsuno, Kanazawa, Ishikawa 920-0942, Japan

e-mail: saitokae63@yahoo.com

T. Kido $\cdot$ R. Naganuma $\cdot$ C. Sakakibara

Faculty of Health Sciences, Institute of Medical,

Pharmaceutical and Health Sciences, Kanazawa University,

Kanazawa, Ishikawa, Japan

K. Tawara

Department of Public Health,

Hyogo College of Medicine, Hyogo, Japan

M. Nishijo - H. Nakagawa

Department of Epidemiology and Public Health,

Kanazawa Medical University, Kanazawa, Ishikawa, Japan

K. Kusama

National Institute of Public Health, Saitama, Japan

P. T. Dung $\cdot$ L. H. Thom $\cdot$ N. N. Hung

10-80 Division, Hanoi Medical University, Ha Noi, Vietnam and TEQ-Total rather than other factors. In the sprayed area, the adjusted $R^{2}$ values of regression were approximately 0.1 . On the other hand, the adjusted $R^{2}$ values in the nonsprayed areas were higher than those in the sprayed area, i.e., between 0.2 and 0.3 , and showed that there were significant associations with body mass index (BMI) in all models.

Conclusions Dioxin exposure was less affected by usual dietary intake in the sprayed area than in the nonsprayed area in Vietnam. It was clear that past exposure rather than present dietary intake may affect present dioxin concentrations in breast milk in the sprayed area in Vietnam. This study suggests that present dioxin concentrations in breast milk were maintained by continuous past exposure even after 30-40 years had passed.

Keywords Dioxin - Breast milk · Food .

Dietary intake $\cdot$ Vietnam

\section{Introduction}

During the Vietnam War, herbicide was sprayed over forests and villages in Central and Southern Vietnam to defoliate the vegetation between 1961 and 1971. The primary mixture used was Agent Orange, which contained 2,3,7,8-tetrachlorodibenzo- $p$-dioxin (2,3,7,8-TCDD) [1]. In general, dioxins refer to polychlorinated dibenzo- $p$-dioxins (PCDDs), polychlorinated dibenzofurans (PCDFs), and coplanar polychlorinated biphenyls (co-PCBs), which are lipophilic compounds that bind to sediment and organic matter in the environment and which have a tendency to accumulate in the fatty tissues of animals and human beings.

It has been reported that the largest source of dioxin contaminants is dietary intake, which accounts for more than 
$90 \%$ of total exposure [2]. Because dioxins are lipid soluble and tend to accumulate in adipose tissue, such as seafood, meat, dairy products, and eggs, the highest concentrations are accumulated in human tissue through the food chain. These studies also suggest that human intake of dioxin has been decreasing for several decades [2-6]. Moreover, several studies have reported positive correlations between the intake of fish and dairy products and dioxin concentrations in breast milk, which are the specific factors influencing the accumulation of dioxin in humans [7-9]. There have, however, been few studies in Vietnam, in spite of the fact that a great deal of herbicide was sprayed there.

The 2003 study of dioxin contamination in food eaten by the Vietnamese people carried out by Schecter et al. [10] was the first document focusing on Agent Orange in the 30-40 years that have passed since the herbicides were sprayed. That study showed a total TEQ for ducks from 286 to $343 \mathrm{ppt}$ wet weight, for chickens from 0.35 to $48 \mathrm{ppt}$ wet weight, and for fish from 0.19 to $66 \mathrm{ppt}$ wet weight, against usual TCDD levels in food of less than $0.1 \mathrm{ppt}$. Moreover, previous studies have reported dioxin in samples of soil, food, human blood, and breast milk in southern Vietnam, even though the Agent Orange contamination occurred 30-40 years before sampling [11-13]. Therefore, there is potential for continuous dioxin exposure through the consumption of fish and meat from contaminated areas.

Previously in Vietnam animal meat was examined; however, the relationship between the consumption of different foods in the diet and the concentration of dioxin in breast milk remains unclear. In addition, nutritional investigations in herbicide-sprayed areas in Vietnam have been inadequate. In Japan the main source of dietary intake of dioxins is fish, while the main sources in Europe and the USA are meat and dairy products, reflecting differences in dietary habits [14]. For these reasons, more detailed information is needed to elucidate the role of routine dietary intake in human exposure to dioxin 30-40 years after Agent Orange use was discontinued in Vietnam. Such information may also prove useful in discussing the prevention of exposure to dioxin through dietary intake. The purpose of this study is to clarify the association between dioxin concentrations in breast milk and food group intake in herbicide-sprayed and nonsprayed areas in Vietnam and also to investigate the specific factors influencing dioxin levels in breast milk.

\section{Materials and methods}

\section{Study population}

Study areas were designated in the north-central area of Vietnam, namely the Cam Chinh commune in the Cam Lo district of Quang Tri province, where herbicides were sprayed during the war, and the Cam Phuc commune in the Cam Xuyen district of Ha Tinh province, which was not sprayed with herbicides during the war. These two communes were once separated by the demilitarized zone (DMZ), the 17th parallel that divided the country during the Vietnam War. A large number of herbicides were sprayed on Cam Chinh commune on the southern side of the DMZ, but they were not sprayed on Cam Phuc commune on the northern side.

In this study, participants were selected from a 20022003 survey of the long-term effects of dioxin on human health. Briefly, this investigation sought to clarify the relationship between dioxins and ecological and human health in Vietnam. Ninety lactating mothers in a sprayed area and 72 lactating mothers in a nonsprayed area were recruited for the investigation in September 2002 and July 2003. Participants were between 20 and 30 years old and provided 10 to $20 \mathrm{ml}$ breast milk. Samples were analyzed for dioxin concentrations. The methods and results of that study were reported previously [15-17].

This survey was conducted in August of 2007 at local district health centers in sprayed and nonsprayed areas, respectively. The interviews were performed using a questionnaire to obtain information on personal characteristics and usual dietary intake by Vietnamese researchers specially trained for this study and who belonged to the 10-80 Division of the Vietnam Ministry of Health.

\section{Measurements}

Information on age, family size, number of children, years of residence, monthly income of husband, level of education, occupation, and smoking status were obtained by the original questionnaire. Body height and weight were measured and body mass index (BMI) was calculated. Dietary intake was assessed by a food frequency questionnaire (FFQ) for Vietnamese. This questionnaire was developed by Kusama et al. [18] as a tool to estimate the habitual nutrient intake of the Vietnamese population. The FFQ is a standard tool in nutritional epidemiology and calculates the intake of nutrients. The intake of calories and nutrients were computed by multiplying the frequency of intake for each food item by the nutrient content of the specified portion size. The reproducibility and validity of this FFQ were established by using 24-h dietary recalls (24HRs) and repeated FFQ. This FFQ consisted of a 116-item food list (foods and dishes) and questions about breakfast and ingredients for dishes eaten at lunch and dinner, and includes foods and dishes, consumption frequency, and portion size. Question responses were given on a scale from 1 to 10 for frequency of consumption: never, less than once per month, 2-3 times per month, 1-2 times 
per week, 3-4 times per week, 5-6 times per week, once per day, 2-3 times per day, 4-5 times per day, and more than 6 times per day. Portion size was categorized into three sizes: small (approximately half of the median size), median, and large (1.5 times the median size). Participants were asked about the average consumption frequency and portion size of each of the food items listed in the questionnaire using a book with full-sized photographs of all food items at the median size for the FFQ interview to improve the accuracy of the estimation of portion size.

\section{Data analysis}

Analysis focused on dioxin concentrations in breast milk in years 2002 and 2003 as a dependent variable. Independent variables were food group intake and subject characteristics. Concentrations of dioxins were presented as toxic equivalent (TEQ) levels. Calculation of TEQ was based on World Health Organization (WHO) 1998 toxic equivalency factors (TEFs) [19].

For each individual, dietary intake was calculated by the Vietnam EIYOKUN dietary assessment system. Each nutrient intake was used to calculate the energyadjusted nutrient intake as the residual from the regression, with nutrient intake as the dependent variable and energy as the independent variable.

Median with 25 and 75 percentiles of dioxin concentrations in breast milk, intake of nutrient and food groups, and subject characteristics were calculated, and differences between herbicide-sprayed and nonsprayed areas were assessed by Student $t$ test, Welch's test, and Wilcoxon signed-rank test. Chi-square was used to compare differences in proportion of education levels, occupation, and smoking status between these areas. The correlation between dioxin concentrations and characteristic data and food group intake were examined using Spearman's correlation coefficients. Before calculating the Pearson correlation coefficient, the distribution of all data was carefully checked, and if any data proved unsuitable for normal distribution, values were log-transformed to improve normality. To identify the major sources of different food group intake contributing to dioxin concentrations in breast milk, stepwise multiple regression analysis of food group intake for dietary habits was used to seek the most significant combination of variables. Data analyses were carried out using JMP ${ }^{\circledR} 6$ software (SAS Institute, Japan), and the statistical level for significant difference was set at 0.05 .

\section{Ethical approvals}

The purpose of the present study was explained thoroughly, and written informed consent was obtained from each participant through their local people's authorities committee. All data were transformed to codes in the analysis process for individuals and they were not identified. To conduct this survey, we obtained permission from the Medical Ethics Committee of Kanazawa University (permission no: Health-89).

\section{Results}

The study population consisted of 122 mothers, namely 80 mothers (participation rate $88.9 \%$ ) in herbicide-sprayed area and 42 mothers (participation rate 58.3\%) in nonsprayed area. Table 1 presents the characteristics of subjects in herbicide-sprayed and nonsprayed areas. Median age was statistically different between the sprayed and nonsprayed areas $(P=0.016)$ at 32.0 and 30.0 years, respectively. Median height (149.9 versus $152.3 \mathrm{~cm}$; $P=0.005)$ and body weight (44.0 versus $45.0 \mathrm{~kg} ; P=$ $0.005)$ were also statistically different between the two areas. However, median BMI was 19.0 and $19.3 \mathrm{~kg} / \mathrm{m}^{2}$, respectively, showing no statistical difference between the two areas. A statistically significant difference in education between the two groups was shown, but there were no significant differences in occupation or smoking status.

Table 2 shows the TEQ levels of PCDDs, PCDFs, and total (PCDDs + PCDFs) in breast milk in sprayed and nonsprayed areas. All dioxin concentrations values were $\log$-transformed to improve normality. There were statistical differences $(P<0.001)$ in TEQ-PCDDs, TEQ-PCDFs, and TEQ-Total between sprayed and nonsprayed areas.

Table 3 summarizes the median intake (with 25 and 75 percentiles) of energy and nutrient and food group per day in sprayed and nonsprayed areas and a comparison of the difference between the two areas. Mean energy intake was not statistically different between sprayed and nonsprayed areas, measuring 1,854 and $1,793 \mathrm{kcal} /$ day, respectively. Intake of lipid $(P=0.036)$ in the nonsprayed area was higher than in the nonsprayed area. In the two areas, intake of fruit and fruit juice was the highest; next came cereals, then meat and meat products, dark-green vegetables, sugars, confectioneries, and soft drinks. Intake of pulses $(P<0.001)$, yellow vegetables $(P<0.011)$, fruit and fruit juice $(P=0.044)$, and alcoholic beverages $(P<0.001)$ in the sprayed area were higher than in the nonsprayed area. On the other hand, there were no cases of significantly higher intake amounts in the nonsprayed area over the sprayed area.

The food group intake that correlated statistically with dioxin concentrations in breast milk in the sprayed area is shown in Table 4. In the sprayed area, no statistical correlations were found between intake of any food group intake and dioxin concentrations in breast milk. In contrast, in the 
Table 1 Characteristics of subjects in herbicide-sprayed and nonsprayed areas
Data are shown as median (25th-75th percentile) or number $(\%)$

$B M I$ body mass index

${ }^{a}$ Wilcoxon signed rank test

b Welch's test

c Chi-square

\begin{tabular}{lccc}
\hline Item & Sprayed area $(n=80)$ & Nonsprayed area $(n=42)$ & $P$ value \\
\hline Age (years) & $32.0(28.0-36.8)$ & $30.0(27.0-32.0)$ & $0.016^{\mathrm{a}}$ \\
Height $(\mathrm{cm})$ & $149.9(147.6-154.3)$ & $152.3(149.5-155.0)$ & $0.005^{\mathrm{a}}$ \\
Weight $(\mathrm{kg})$ & $44.0(40.0-46.4)$ & $45.0(42.8-50.3)$ & $0.005^{\mathrm{b}}$ \\
BMI $\left(\mathrm{kg} / \mathrm{m}^{2}\right)$ & $19.0(17.8-20.9)$ & $19.3(18.4-20.8)$ & $0.268^{\mathrm{a}}$ \\
Family size (people) & $5.0(4.0-6.0)$ & $4.0(4.0-5.0)$ & $0.001^{\mathrm{a}}$ \\
Number of children (people) & $2.0(2.0-3.0)$ & $2.0(2.0-2.3)$ & $0.073^{\mathrm{a}}$ \\
Residence period (years) & $29.0(18.8-33.0)$ & $27.5(15.8-32.0)$ & $0.301^{\mathrm{a}}$ \\
Monthly income of husband $\left(\times 10^{4}\right.$ VND) & $100(76-150)$ & $100(50-150)$ & $0.067^{\mathrm{a}}$ \\
Education level & & & \\
$\quad<$ Elementary school & $23(28.8 \%)$ & $23(54.8 \%)$ & $0.006^{\mathrm{c}}$ \\
$>$ Junior high school & $57(71.3 \%)$ & $19(45.2 \%)$ & \\
Occupation & $70(87.5 \%)$ & $36(85.7 \%)$ & $0.783^{\mathrm{c}}$ \\
Farmer & $10(12.5 \%)$ & $6(14.3 \%)$ & \\
$\quad$ Other & $3(3.8 \%)$ & $0(0 \%)$ & - \\
Smoking status & $77(96.3 \%)$ & $41(100 \%)$ & \\
Current & &
\end{tabular}

Table 2 Comparison of dioxin concentrations (pgTEQ/gFat) in breast milk between herbicide-sprayed and nonsprayed areas

\begin{tabular}{lcll}
\hline Dioxins & Sprayed area $(n=80)$ & Nonsprayed area $(n=42)$ & $P$ value \\
\hline TEQ-PCDDs & $4.54(2.95-6.39)$ & $1.88(1.55-2.34)$ & $<0.001^{\text {a }}$ \\
TEQ-PCDFs & $5.06(3.37-7.91)$ & $1.99(1.40-2.39)$ & $<0.001^{\text {b }}$ \\
TEQ-Total & $10.13(6.46-14.20)$ & $3.80(2.97-4.81)$ & $<0.001^{\text {b }}$ \\
\hline
\end{tabular}

Data are shown as median (25th-75th percentile). Data of TEQ-PCDFs are log-transformed to improve normality

${ }^{\text {a }} t$ test

b Wilcoxon signed-rank test

nonsprayed area positive statistical correlations were shown between intake amounts of fats $(r=0.35, P=0.023)$, shellfish and shellfish products $(r=0.31, P=0.048)$, milk and dairy products $(r=0.31, P=0.043)$, and seasonings $(r=0.39, \quad P=0.011)$ and breast milk TEQ-PCDFs. Moreover, soybean product $(r=0.32, P=0.039)$ and seasoning $(r=0.32, P=0.042)$ intake were positively correlated with breast milk TEQ-Total. However, no food group intake was significantly correlated with breast milk TEQ-PCDDs.

Multiple linear regression analysis was used to determine which food groups were significantly correlated with breast milk TEQ-PCDDs, TEQ-PCDFs, and TEQ-Total as a dependent variable. The analysis focused on breast milk TEQ-PCDDs, TEQ-PCDFs, and TEQ-Total. Independent variables were subject characteristics (area, age, BMI, and monthly income of husband) and food group intake. To reduce the number of variables in the multivariate model, prognostic factors were included in the model by mixeddirection stepwise analysis. Stepwise criteria were that the variable could enter the equation when its $F$ statistic probability was greater than 2.0.
Table 5 presents the multiple linear regression in all subjects (sprayed and nonsprayed areas). Multiple linear regression analysis found that area was the only variable associated with TEQ-PCDDs $\left(\beta=0.610\right.$, adjusted $R^{2}=$ $0.367)$, TEQ-PCDFs ( $\beta=0.643$, adjusted $\left.R^{2}=0.408\right)$, and TEQ-Total $\left(\beta=0.647\right.$, adjusted $\left.R^{2}=0.413\right)$.

In the sprayed area the associations between food group intake and TEQ-PCDDs (adjusted $R^{2}=0.072$ ), TEQPCDFs (adjusted $R^{2}=0.052$ ), and TEQ-Total (adjusted $\left.R^{2}=0.026\right)$ concentrations showed that adjusted $R^{2}$ values of regression were small (Table 6).

In the nonsprayed area the adjusted $R^{2}$ values of regression were higher than in the sprayed area for all models using TEQ-PCDDs (adjusted $R^{2}=0.216$ ), TEQPCDFs (adjusted $R^{2}=0.296$ ), and TEQ-Total (adjusted $R^{2}=0.182$ ) as a dependent variable (Table 6). In the nonsprayed area all models showed an association between BMI and TEQ-PCDDs, TEQ-PCDFs, and TEQ-Total $(\beta=0.333,0.413,0.349)$. TEQ-PCDDs was most highly associated with intake of yellow vegetables $(\beta=0.442)$, and TEQ-PCDFs was associated with intake of shellfish and shellfish products $(\beta=0.350)$, while no association 
Table 3 Dietary intake from FFQ in herbicide-sprayed and nonsprayed areas

\begin{tabular}{|c|c|c|c|}
\hline Dietary intake & Sprayed area $(n=80)$ & Nonsprayed area $(n=42)$ & $P$ value $^{\mathrm{a}}$ \\
\hline Energy & $1854(1440-2423)$ & 1793 (1389-2225) & 0.620 \\
\hline Protein & $87.2(78.5-92.9)$ & $87.6(83.3-95.7)$ & 0.227 \\
\hline Lipid & $52.8(45.3-60.0)$ & $56.7(52.3-61.7)$ & 0.036 \\
\hline Carbohydrate & $290.4(270.4-312.4)$ & $276.9(269.1-294.7)$ & 0.059 \\
\hline Fiber & $12.8(10.9-16.0)$ & $15.0(12.4-19.4)$ & 0.018 \\
\hline Cereals & $255.2(205.5-330.6)$ & $239.9(185.6-324.6)$ & 0.435 \\
\hline Potatoes and starches & $31.0(10.5-66.0)$ & $40.8(25.6-70.5)$ & 0.070 \\
\hline Nuts and seeds & $25.0(15.1-26.2)$ & $25.0(12.8-25.0)$ & 0.984 \\
\hline Pulses & $0(0-27.7)$ & $0(0-0)$ & $<0.001$ \\
\hline Soybean products & $15.1(7.6-30.6)$ & $15.1(7.6-30.2)$ & 0.617 \\
\hline Dark-green vegetables & $175.4(126.8-254.0)$ & $197.2(120.8-299.7)$ & 0.309 \\
\hline Yellow vegetables & $45.3(26.8-69.3)$ & $32.0(13.8-43.9)$ & 0.011 \\
\hline Other vegetables & $126.8(86.1-207.1)$ & $94.0(57.9-179.0)$ & 0.063 \\
\hline Fruit and fruit juice & $504.7(402.0-694.1)$ & $459.7(290.1-604.3)$ & 0.044 \\
\hline Fats & $6.3(2.7-12.0)$ & $7.2(1.7-10.8)$ & 0.436 \\
\hline Vegetable oils & $16.1(10.5-21.6)$ & $15.0(8.9-23.0)$ & 0.663 \\
\hline Meat and meat products & $206.0(130.1-316.7)$ & $262.1(172.0-372.3)$ & 0.125 \\
\hline Fish and fish products & $52.6(33.4-84.6)$ & $59.6(30.7-109.0)$ & 0.777 \\
\hline Shellfish and shellfish products & $14.0(5.1-31.0)$ & $13.9(5.0-28.3)$ & 0.944 \\
\hline Eggs & $30.2(16.3-49.4)$ & $33.4(12.5-76.0)$ & 0.668 \\
\hline Milk and dairy products & $0.6(0-7.1)$ & $0(0-18.8)$ & 0.984 \\
\hline Sugars, confectioneries, soft drink & $159.5(122.3-222.8)$ & $162.1(112.9-183.9)$ & 0.236 \\
\hline Alcohol beverages & $0.4(0-7.1)$ & $0(0-0)$ & $<0.001$ \\
\hline Seasonings & $41.3(28.2-54.1)$ & $44.2(30.1-57.0)$ & 0.508 \\
\hline
\end{tabular}

Data are shown as median (25th-75th percentile). Units of energy data are kcal/day; others are in g/day. Nutrient intake is adjusted for energy intake by the residual method

${ }^{a}$ Wilcoxon signed-rank test

was found between TEQ-Total and any factor except BMI.

\section{Discussion}

This study adopted the concentration data for PCDDs and PCDFs in breast milk measured in years 2002 and 2003. Consequently, the lapse of time between data collection and this study is 4-5 years. Normally, coincident measure of dioxin concentrations and dietary survey are required. Nevertheless, the half-life of dioxin in human body has been estimated to be as long as 7.5 years [20]; therefore, the decrease in dioxin concentrations in subject breast milk at the time of data collection and the present study can be expected to exhibit no great difference. In addition, the economic-social and food distribution systems in the study areas have not undergone great change during the 5 years between data collection and the present study. Furthermore, the FFQ estimates long-term intake for usual dietary habit. Hence, we consider it possible to clarify the association between dioxin concentrations in 2002-2003 and present dietary intake in spite of the limitations of this method.

Correlation coefficients between dioxin concentrations in breast milk and food group intake were shown by FFQ nutrition survey in sprayed and nonsprayed areas in Vietnam. Although the mean value and range of dioxin concentrations in foods were different among countries, previous studies have reported that the main source of dietary intake of dioxin is adipose tissue and fish [2-4]. This process of biological condensation explains the high accumulation of dioxin in animals.

However, low dioxin exposure was seen in these studies under normal conditions, making it difficult to compare this study with previous studies due to the fact that our research areas were sprayed by herbicides, including dioxin, during the Vietnam War. There were no statistical correlations between dioxin concentrations and the intake of each food group in the sprayed area. In contrast, in the nonsprayed area, there were statistical relationships between the intake of fat, shellfish and shellfish products, milk and dairy 
Table 4 Spearman correlation coefficients between dioxin concentrations in breast milk and food group intake

\begin{tabular}{|c|c|c|c|c|c|c|c|c|c|c|c|c|}
\hline \multirow[t]{3}{*}{ Food group } & \multicolumn{6}{|c|}{ Sprayed area $(n=80)$} & \multicolumn{6}{|c|}{ Nonsprayed area $(n=42)$} \\
\hline & \multicolumn{2}{|c|}{ TEQ-PCDDs } & \multicolumn{2}{|c|}{ TEQ-PCDFs } & \multicolumn{2}{|c|}{ TEQ-Total } & \multicolumn{2}{|c|}{ TEQ-PCDDs } & \multicolumn{2}{|c|}{ TEQ-PCDFs } & \multicolumn{2}{|c|}{ TEQ-Total } \\
\hline & $r$ & $P$ value & $r$ & $P$ value & $r$ & $P$ value & $r$ & $P$ value & $r$ & $P$ value & $r$ & $P$ value \\
\hline Cereals & -0.02 & 0.877 & -0.12 & 0.281 & -0.10 & 0.362 & -0.08 & 0.606 & 0.16 & 0.304 & 0.05 & 0.745 \\
\hline Potatoes and starches & 0.09 & 0.438 & 0.06 & 0.626 & 0.07 & 0.522 & -0.01 & 0.949 & 0.16 & 0.314 & 0.07 & 0.673 \\
\hline Nuts and seeds & -0.14 & 0.211 & -0.14 & 0.217 & -0.15 & 0.185 & 0.19 & 0.226 & 0.18 & 0.250 & 0.20 & 0.207 \\
\hline Pulses & 0.02 & 0.832 & 0.06 & 0.573 & 0.05 & 0.641 & 0.20 & 0.208 & 0.19 & 0.238 & 0.20 & 0.203 \\
\hline Soybean products & 0.01 & 0.901 & 0.03 & 0.803 & 0.02 & 0.848 & 0.27 & 0.079 & 0.28 & 0.076 & 0.32 & 0.039 \\
\hline Dark-green vegetables & 0.02 & 0.866 & 0.07 & 0.534 & 0.07 & 0.552 & 0.10 & 0.545 & 0.06 & 0.722 & 0.08 & 0.618 \\
\hline Yellow vegetables & -0.11 & 0.311 & -0.16 & 0.148 & -0.15 & 0.176 & 0.17 & 0.275 & 0.26 & 0.097 & 0.23 & 0.149 \\
\hline Other vegetables & 0.05 & 0.690 & 0.10 & 0.359 & 0.11 & 0.354 & 0.02 & 0.923 & 0.09 & 0.583 & 0.07 & 0.653 \\
\hline Fruit and fruit juice & -0.05 & 0.648 & -0.07 & 0.520 & -0.07 & 0.538 & 0.00 & 0.996 & 0.20 & 0.213 & 0.11 & 0.484 \\
\hline Fats & -0.10 & 0.401 & -0.12 & 0.275 & -0.12 & 0.270 & 0.15 & 0.346 & 0.35 & 0.023 & 0.27 & 0.079 \\
\hline Vegetable oils & -0.07 & 0.537 & -0.05 & 0.652 & -0.06 & 0.608 & 0.06 & 0.723 & 0.30 & 0.051 & 0.21 & 0.188 \\
\hline Meat and meat products & -0.02 & 0.854 & -0.01 & 0.949 & -0.01 & 0.908 & -0.04 & 0.786 & 0.13 & 0.418 & 0.06 & 0.693 \\
\hline Fish and fish products & 0.03 & 0.807 & 0.14 & 0.222 & 0.10 & 0.397 & 0.19 & 0.237 & 0.10 & 0.549 & 0.15 & 0.344 \\
\hline Shellfish and shellfish products & 0.00 & 0.989 & -0.05 & 0.674 & -0.03 & 0.801 & 0.07 & 0.681 & 0.31 & 0.048 & 0.23 & 0.148 \\
\hline Eggs & 0.14 & 0.202 & -0.02 & 0.882 & 0.06 & 0.586 & -0.16 & 0.320 & 0.12 & 0.441 & -0.03 & 0.838 \\
\hline Milk and dairy products & 0.14 & 0.207 & 0.07 & 0.532 & 0.10 & 0.365 & 0.12 & 0.446 & 0.31 & 0.043 & 0.24 & 0.122 \\
\hline Sugars, confectioneries, soft drinks & -0.02 & 0.837 & -0.06 & 0.572 & -0.06 & 0.569 & 0.06 & 0.727 & 0.15 & 0.358 & 0.13 & 0.419 \\
\hline Alcohol beverages & 0.11 & 0.324 & 0.05 & 0.651 & 0.09 & 0.446 & 0.05 & 0.754 & 0.15 & 0.335 & 0.10 & 0.531 \\
\hline Seasonings & -0.05 & 0.658 & -0.07 & 0.520 & -0.07 & 0.522 & 0.18 & 0.246 & 0.39 & 0.011 & 0.32 & 0.042 \\
\hline
\end{tabular}

All data are log-transformed to improve normality

$r$ correlation coefficients

Table 5 Stepwise multiple linear regression of TEQ-PCDDs, TEQPCDFs, and TEQ-Total levels in breast milk and food group intake in all subjects $(n=122)$

\begin{tabular}{llll}
\hline Variables & Standardized coefficients & $P$ value & Adjusted $R^{2}$ \\
\hline $\begin{array}{llll}\text { TEQ-PCDDs } \\
\text { Constant }\end{array}$ & & $<0.0001$ & 0.367 \\
Area & 0.610 & $<0.0001$ & \\
TEQ-PCDFs & & & \\
Constant & & $<0.0001$ & 0.408 \\
Area & 0.643 & $<0.0001$ & \\
TEQ-Total & & & \\
Constant & & $<0.0001$ & 0.413 \\
Area & 0.647 & $<0.0001$ & \\
\hline
\end{tabular}

All data are log-transformed for analysis. Variables: area code ( 1 for sprayed area, 0 for nonsprayed area), age, BMI, monthly income of husband, cereals, potatoes and starches, nuts and seeds, pulses, soybean products, dark-green vegetables, yellow vegetables, other vegetables, fruit and fruit juice, fats, vegetable oils, meat and products, fish and products, shellfish and products, eggs, milk and dairy products, sugars, confectioneries, soft drink, alcohol beverages, seasonings

products, and seasonings with TEQ-PCDFs in breast milk, although the correlation coefficient was small, and the intake of soybean products and seasoning with TEQ-Total in breast milk. However, all correlation coefficients were approximately 0.3 ; therefore, these results do not show a clear relation between dioxin concentrations in breast milk and food group intake.

The difference in correlations between dioxin concentrations in breast milk and food group intake in the two areas is attributed to the presence or absence of exposure to herbicide. In the sprayed area, although there is dietary exposure to dioxins in the sprayed and nonsprayed areas similar to studies by Huisuman et al. [7] and Takekuma et al. [8], past exposure may act as a stronger factor than present dietary intake in the sprayed area. Hence, it is implied that there was no statistical association between dioxin concentrations in breast milk and present dietary intake.

Multiple regression analysis showed that location (sprayed or nonsprayed area) made the highest contribution to dioxin concentrations in breast milk. It is noted that difference of location is a stronger factor than present dietary intake; that is, it is the strongest contributor to dioxin concentrations in breast milk, regardless of type. This indication stems from the fact that there was no statistical correlation between breast milk dioxin concentrations in simple correlation coefficients, and the fact that the economic-social systems of both areas are similar.

Incidentally, because the average age of participants in this study was $31.8 \pm 5.5$ years, it is suggested that present 
Table 6 Stepwise multiple linear regression of TEQ-PCDDs, TEQPCDFs, and TEQ-Total levels in breast milk and food group intake in herbicide-sprayed and nonsprayed areas

\begin{tabular}{llll}
\hline Variables & $\begin{array}{l}\text { Standardized } \\
\text { coefficients }\end{array}$ & $P$ value & $\begin{array}{l}\text { Adjusted } \\
R^{2}\end{array}$ \\
\hline
\end{tabular}

Sprayed area $(n=80)$

TEQ-PCDDs

\begin{tabular}{|c|c|c|c|}
\hline Constant & & $<0.0001$ & 0.072 \\
\hline Fats & -0.308 & 0.038 & \\
\hline Eggs & 0.262 & 0.064 & \\
\hline Alcohol beverages & 0.231 & 0.055 & \\
\hline Nuts and seeds & -0.206 & 0.073 & \\
\hline \multicolumn{4}{|l|}{ TEQ-PCDFs } \\
\hline Constant & & 0.000 & 0.052 \\
\hline Fats & -0.204 & 0.097 & \\
\hline Fish and products & 0.167 & 0.135 & \\
\hline Alcohol beverages & 0.159 & 0.188 & \\
\hline Nuts and seeds & -0.145 & 0.199 & \\
\hline \multicolumn{4}{|l|}{ TEQ-Total } \\
\hline Constant & & $<0.0001$ & 0.026 \\
\hline Nuts and seeds & -0.197 & 0.080 & \\
\hline \multicolumn{4}{|l|}{ Jonsprayed area $(n=42)$} \\
\hline \multicolumn{4}{|l|}{ TEQ-PCDDs } \\
\hline Constant & & 0.636 & 0.216 \\
\hline Yellow vegetables & 0.442 & 0.011 & \\
\hline BMI & 0.333 & 0.025 & \\
\hline $\begin{array}{l}\text { Sugars, confectioneries, } \\
\text { soft drinks }\end{array}$ & -0.285 & 0.083 & \\
\hline Soybean products & 0.238 & 0.116 & \\
\hline \multicolumn{4}{|l|}{ TEQ-PCDFs } \\
\hline Constant & & 0.009 & 0.296 \\
\hline BMI & 0.413 & 0.005 & \\
\hline Shellfish and products & 0.350 & 0.020 & \\
\hline Seasonings & 0.269 & 0.074 & \\
\hline Pulses & 0.231 & 0.096 & \\
\hline \multicolumn{4}{|l|}{ TEQ-Total } \\
\hline Constant & & 0.627 & 0.182 \\
\hline BMI & 0.349 & 0.022 & \\
\hline Yellow vegetables & 0.271 & 0.073 & \\
\hline Soybean products & 0.267 & 0.085 & \\
\hline
\end{tabular}

All data are log-transformed for analysis. Variables: age, BMI, cereals, potatoes and starches, nuts and seeds, pulses, soybean products, dark-green vegetables, yellow vegetables, other vegetables, fruit and fruit juice, fats, vegetable oils, meat and products, fish and products, shellfish and products, eggs, milk and dairy products, sugars/confectioneries/soft drinks, alcohol beverages, seasonings

dioxin accumulation in human tissue was influenced by breast-feeding by mothers who were exposed directly to a herbicide, and that dioxin concentrations in breast milk were influenced by intake of foods with high concentrations of dioxin, even if almost all subjects were born after
1977, well after the cessation of herbicide spraying. Schecter et al. [21] reported that serum dioxin concentrations in the sprayed area were higher than those in the nonsprayed area in a comparison of children who were born in the sprayed area and who moved to the sprayed area from the nonsprayed area after the spraying of herbicide. Furthermore, Tada [22] suggested that dioxin concentrations in adults might affect those in infants. For these reasons, it is implied that dioxin concentrations in breast milk are not influenced by present dietary intake.

Multiple regression analysis distinguishes area, given the fact that the adjusted $R^{2}$ values of regression were small, namely approximately 0.1 , though some associations were statistically significant in sprayed area. We could not explain the influencing factor in dioxin concentrations in breast milk. In contrast, the adjusted $R^{2}$ values in the nonsprayed area were higher than those of the sprayed area, that is, between 0.2 and 0.3 , and there were differences between the two areas. Although standardized coefficients were different for each model, there were associations with BMI in all models in the nonsprayed area. Body burdens for lipophilic chemicals are dependent on the weight and body fat of an animal. Dioxins are all highly lipophilic, resulting in their partitioning into fatty tissues [23]. One physiologically based pharmacokinetic model accounts for changes in BMI over time, with higher BMI being related to longer half-life for TCDD [24]. The results of the present study are consistent with these previous studies.

In consequence it was made clear that past exposure rather than present dietary intake affects present dioxin concentrations in breast milk in the sprayed area in Vietnam. In contrast, it is suggested that present dietary intake and BMI might affect those in the nonsprayed area. Therefore, dioxin exposure was less affected by usual dietary intake in the sprayed area than in the nonsprayed area in Vietnam. However, in order to clarify the relationship, more detailed information on background dioxin exposure, namely food distribution systems, waste disposal methods, and pesticide use, are needed. Furthermore, past accumulation of dioxin and reduction of dioxin concentrations in the body are issues to be considered. In addition, continued study is necessary due to the great potential for continuous exposure to dioxins through contamination of foods in highexposure areas, called "hot spots," in spite of the fact that this study did not indicate any relationship between dioxin concentrations in breast milk and dietary intake.

Acknowledgments This study was supported by grants from the Japan Society for the Promotion of Science [Grant-in-Aid for Scientific Research, (B) no. 17406016 and Grant-in-Aid for Scientific Research (A) no. 19209021]. The authors are deeply indebted to members of the 10-80 division and staff members of the local district health centers in Vietnam for their cooperation and encouragement during the study. 


\section{Appendix}

See Table 7.

Table 7 List of food items (part 1) and seasoning and cooking methods (part 2) for the food frequency questionnaire for Vietnamese adults

\section{Part 1}

Cereals

1 Steamed plain rice

2 Bread (French type)

3 Bread (sandwich type)

4 Bread (French type) with pork meat

5 Bread (French type) with canned fish

6 Bread (French type) with pemicant

(smoke-dried pork, shaved)

7 Bread (French type) with fried egg

8 Sandwich

9 Rice noodle (thick type) with pork

10 Rice noodle with beef and pork

11 Rice noodle with crab

12 Rice noodle with duck and bamboo shoots

13 Rice noodle with pork, fish, squid, and shrimp

14 Rice noodle with pork and pork products

15 Rice noodle with crab and pork products

16 Rice noodle (flat type) with pork

17 Rice noodle with beef

18 Rice noodle with chicken

19 Rice noodle with beef curry

20 Fried rice noodle with pork and entrails

21 Rice noodle and Chinese noodle with pork

22 Rice noodle with pork and pork entrails

23 Soup of noodle

24 Rice with pork skin

25 Rice with omelet

26 Rice with grilled pork

27 Pork and vegetable rolled cake

28 Fried rice with vegetable

29 Rice gruel with pork blood

30 Rice gruel with pork entrails

31 Glutinous rice with black bean

32 Glutinous rice with mung bean

33 Glutinous rice with peanut

34 Glutinous rice with meat

Vegetables and potatoes

35 Amaranth, Jute potherb

36 Swamp cabbage, Sweet potato leaves

37 Mustard green, Chinese cabbage

38 Malabar nightshade

39 Crown-daisy

40 Chinese leek

41 Wort, India penny

42 Cabbage

43 French bean

44 Green pepper

45 Tomato
46 Carrot

47 Ash gourd, wax gourd

48 Bitter gourd

49 Pumpkin squash

50 Gourd

51 Cucumber

52 Broccoli

53 White potato

54 Chinese yam

55 Sweet potato

Meat

56 Pork lean

57 Pork upper leg

58 Pork medium fat

59 Pork rib

60 Pork lower leg

61 Pork fat

62 Beef

63 Chicken

64 Duck

65 Pork blood

Fish and shellfish

66 Scad, anchovy

67 Snake head fish

68 Mullet

69 Goby

70 Tuna

71 Fat fish

72 Tilapia

73 Mackerel

74 Shrimp

75 Squid

76 Fresh water crab

Eggs

77 Hen egg

78 Duck egg

Tofu (soybean curd)

79 Tofu (soybean curd) fried

80 Tofu (soybean curd) raw

Dairy foods

81 Fresh milk without sugar

82 Fresh milk with sugar

83 Soybean milk

84 Milk powder, whole

85 Skim milk

86 Yogurt

87 Condensed milk
Fruit

88 Dragon fruit

89 Banana

90 Papaya

91 Pomelo

92 Longan

93 Orange

94 Water melon

95 Pear

96 Grape

97 Guava

98 Apple

Beverages

99 Bear

100 Soft drink

101 Fruit shake juice

102 Lemon juice

103 Green leaves juice

104 Orange juice

105 Coconut juice with kernel

106 Coffee

107 Instant coffee

108 Instant coffee with milk and sugar

Sweets and dessert

109 Glutinous rice cake with mung bean and pork fat

110 Steamed rice cake

111 Baked sweet Vietnamese style

112 Sponge cake

113 Sweetened maize, banana, yam, and sweet potato

114 Sweetened bean and glutinous soup

115 Sweetened bean soup

116 Tofu (soybean curd) with sweet syrup

\section{Part 2}

Cooking methods for dishes

1 Boiled with seasoning

2 Fried

3 Sauteed

4 Boiled

5 Soup

6 Grilled

7 Salted

8 Salad

Table seasoning

1 Fish sauce

2 Salted

3 Soybean sauce 


\section{References}

1. Stellman JM, Stellman SD, Christian R, Weber T, Tomasallo C. The extent and patterns of usage of Agent Orange and other herbicides in Vietnam. Nature. 2003;422(6933):681-7.

2. Liem AK, Fürst P, Rappe C. Exposure of populations to dioxins and related compounds. Food Addit Contam. 2000;17:241-59.

3. SOOP EU/EC Task 2.3.5 report. Assessment of dietary intake of dioxins and related PCBs by the population of EU member states. European Commission. Directorate-General Health and Consumer Protection, Brussels, Belgium; 2000.

4. James RS, Martin DR. Dioxin and Dioxinlike PCBs in food. In: Schecter A, Gasiewicz TA, editors. Dioxin and health. Canada: Wiley; 2003. p. 89-136.

5. Mato Y, Suzuki N, Katatani N, Kadokami K, Nakano T, Nakayama S, et al. Human intake of PCDDs, PCDFs, and dioxin like PCBs in Japan, 2001 and 2002. Chemosphere. 2007;67: S247-55.

6. Bilau M, Matthys C, Baeyens W, Bruckers L, Backer GD, Hond $\mathrm{ED}$, et al. Dietary exposure to dioxin-like compounds in three age groups: results from the Flemish environment and health study. Chemosphere. 2008;70:584-92.

7. Huisman M, Eerenstein SE, Koopman-Esseboom C, Brouwer M, Fidler V, Muskiet FA, et al. Perinatal exposure to polychlorinated biphenyls and dioxins through dietary intake. Chemosphere. 1995;31:4273-87.

8. Takekuma M, Saito K, Ogawa M, Matumoto R, Kobayashi S. Levels of PCDDs, PCDFs and Co-PCBs in human milk in Saitama, Japan, and epidemiological research. Chemosphere. 2004;54:127-35.

9. Guan P, Tajimi M, Uehara R, Watanabe M, Oki I, Ojima T, et al. Associations between dietary intake and breast milk dioxin levels in Tokyo. Jpn Pediatr Int. 2005;47:560-6.

10. Schecter A, Quynh HT, Pavuk M, Päpke O, Malisch R, Constable JD. Food as a source of dioxin exposure in the residents of Bien Hoa City, Vietnam. J Occup Environ Med. 2003;45:781-8.

11. Dwernychuk LW, Cau HD, Hatfield CT, Boivin TG, Hung TM, Dung PT, et al. Dioxin reservoirs in southern Viet Nam-A legacy of Agent Orange. Chemosphere. 2002;47:117-37.

12. Schecter A, Quynh T, Päpke O, Tung KC, Constable JD. Agent Orang, Dioxins, and other chemicals of concern in Vietnam: update 2006. J Occup Environ Med. 2006;48:408-13.
13. Mai TA, Doan TV, Tarradellas J, de Alencastro LF, Grandjean D. Dioxin contamination in soils of Southern Vietnam. Chemosphere. 2007;67:1802-7.

14. Thoyama C, Masho R. The establishment of tolerable intake levels and the current situation of the risk assessment of dioxin and related compounds. Jpn J Hyg. 2005;60:60-9. (in Japanese).

15. Kido T, Maruzeni S, Suzuki H, Odamae Y, Muranaka M, Naganuma R. Five years studies on the long term effects of war Agent Orange/dioxin on human health in Vietnam. Persistent Organic Pollutants (POPs) Research in Asia; 2008. p. 445-50.

16. Tawara K, Honda R, Nishijo M, Nakagawa H. Pretreatment procedure of dioxin analysis for a small volume of human breast milk. J Kanazawa Med Univ. 2003;28:17-25.

17. Tawara K, Nishijo M, Honda R, Maruzeni S, Seto T, Kido T, et al. Effects of maternal dioxin exposure on newborn size at birth among Japanese mother-infant pairs. Environ Health Prev Med. 1009;14:88-95.

18. Kusama K, Le DS, Hanh TT, Takahashi K, Hung NT, Yoshiike $\mathrm{N}$, et al. Reproducibility and validity of a food frequency questionnaire among Vietnamese in Ho Chi Minh City. J Am Coll Nutr. 2005;24:466-73.

19. Van den Berg M, Birnbaum L, Bosveld AT, Brunstrom B, Cook P, Feeley M. Toxic Equivalency Factors (TEFs) for PCBs, PCDDs, PCDFs for humans and wildlife. Environ Health Perspect. 1998;106:775-92.

20. Michalek JE, Tripathi RC. Pharmacokinetics of TCDD in veterans of Operation Ranch Hand: 15-years follow-up. J Toxicol Environ Health A. 1999;57:369-78.

21. Schecter A, Dai LC, Päpke O, Prange J, Constable JD, Matsuda $\mathrm{M}$, et al. Recent dioxin contamination from Agent Orange in residents of a southern Vietnam city. J Occup Environ Med. 2001;43:435-43.

22. Tada $H$. The study on effect of dioxin concentration in breast milk for infants. Health and Labour Sciences Research Grants report of 2003; 2003 (in Japanese).

23. Schecter A, Gasiewicz TA. Dioxin and health. Hoboken: Wiley; 2003.

24. Thomaseth K, Salvan A. Estimation of occupational exposure to 2, 3, 7, 8-tetrachlorodibenzo- $p$-dioxin using a minimal physiologic toxicokinetic model. Environ Health Perspect. 1998;106 (Suppl.2):743-53. 